\title{
Development and standardization of accessible design technologies that address the needs of senior citizens
}

\author{
- Product design methodology based on measurements of \\ domestic sounds and hearing characteristics
}

\author{
Kenji Kurakata* and Ken Sagawa
}

[Translation from Synthesiology, Vol.1, No.1, p.15-23 (2008)]

\begin{abstract}
With the recent trend of decreased birthrate and increased aging population, design that can be used by as many people as possible including the elderly, or accessible design, has been incorporated in consumer product designs. The authors have developed and propagated accessible design technology through the establishment of Japanese Industrial Standard (JIS) based on auditory and visual functions of elderly people. This paper uses JIS S 0014, a standard for adjustment method of sound volume of auditory signals, to describe the research process that leads to the standardization of accessible design from the perspective of Full Research.
\end{abstract}

Keywords : Elderly (older person/people), hearing, vision, auditory signal, standardization, Japanese Industrial Standard

\section{Introduction}

With the recent trend of decreased birthrate and increased aging population, that is, less young people and more elderly, the main users of consumer products including home electric appliances, information technology devices, and office appliances are shifting from young to elderly. Conventionally, the users were assumed to be young people when designing such products. However, in the society of decreased birthrate and increased aging population, there is more demand for "accessible design" or design that can be used by as many people as possible including the elderly.

This is not merely a superficial issue of difference in design preference between the generations. As the number of elderly users increase, there is a rising concern for cases of product misuse due to failure to see or hear information necessary to use the product correctly. Therefore, appropriate display of product use instruction to maintain high safety level is demanded ever more than before. Also, there is a tendency for the elderly to avoid using new products because they feel uneasy about using them safely. This may hamper replacement by purchase, and the entire market of the product may gradually shrink. However, looking at the situation from a different angle, this great shift in demographic structure is a good chance to pioneer a new market. Now, there is increased activity in developing new products or changing design specifications for the elderly who are new users untargeted before. Ever since 1990, interest in design method that addresses the characteristics of the elderly has been increasing in various product categories such as consumer products and office appliances.

With this social background, the authors have been involved in drafting and establishing the standards for auditory and visual functions in the Guidelines for the Elderly and People with Disabilities of the Japanese Industrial Standard (JIS) ${ }^{[1,2]}$. In this paper, first, the significance and the necessity of accessible design standardization are explained. Next, using as example JIS S $0014^{[3]}$, a standard for auditory signal of consumer products on which the authors worked to establish, the research process that leads to the standardization of accessible design technology will be discussed from the perspective of Full Research.

\section{Significance and necessity of standardization}

The authors have aimed for standardization through establishment of JIS and other standards ever since the start of development of accessible technology. One of the reasons is because, as elderly-friendly products started to appear in the market, confusions developed due to differences in design specifications by manufacturers or by product types, as well as to a gradual increase of inadequately designed products that carried the elderly-friendly label. The establishment of Guidelines for the Elderly and People with Disabilities series occurred due to strong requests from government and the industry that wished to improve the situation.

Aside from such a situation, there are many advantages in conducting ergonomic technology development including accessible design technology, with standardization in mind from the very beginning. First, since human characteristics are multidimensional, there are many factors to consider even when developing one technology. In case of auditory signal, aging characteristic of hearing is the subject of study, but to design sound that is easy to hear and recognize, the effects of at least three factors including frequency, sound pressure level, and time pattern must be studied sequentially. Academically, experimental condition for each

Institute for Human Science and Biomedical Engineering, AIST Tsukuba Central 6,Tsukuba,Ibaraki 305-8566, Japan * E-mail :kurakata-k@aist.go.jp 
factor can be set, and hearing characteristic can be broken down finely and studied for each condition. However, such piecemeal knowledge is not useful in actual design. The process of "integrating" individual research results into one methodology is essential for completed design technology.

Also, if the goal is the development of a technology that can be used effectively in actual practice, the result should not be researcher's self-indulgence. Design precision can be improved limitlessly by using complex design method and by creating intricate model of human characteristics. However, the more precise the model, the range of application becomes narrower. This will not lead to the development of technology that can be applied to diverse domestic environments. Moreover, good precision and usability of method often conflict with each other. Even if it is a good design technology, it is meaningless unless it is used widely in actual practice.

At the drafting stage of the standard, studies are conducted from aspects of academic accuracy and technological efficacy. The comments of on-site technologists as well as researchers are incorporated to create a standard methodology. The method standardized in this manner is expected to be used as a tool in actual design in wide-ranging fields over the long run.

\section{Auditory signal of consumer product and its problem}

"Auditory signal" discussed in this paper is sound emitted by the product itself or by the remote controller to notify the user of the operational status of the product. This includes sound set off as feedback when pressing a button on the control panel, sound to notify the end of action of the product, or sound to notify operation error or abnormality of the device. The usability of the product is improved and the occurrence of improper use can be lowered by appropriately designing auditory signals.

However, conventional auditory signal did not necessarily function as intended, and many became sources of claims from the users. The content of the claims can be roughly divided into two (Figure 1). (1) Cannot hear the signal: "I thought the signal went off but couldn't hear it". (2) Do not understand the meaning of the signal: "I can hear the signal, but don't know what it's supposed to mean".

In designing auditory signals, three levels of adjustment can be made acoustically: (a) frequency (pitch of sound), (b) sound pressure level (volume of sound), and (c) time pattern (time change of sound). If the auditory signal was appropriately designed on each level, aforementioned claims could have been avoided.
Inability to hear the auditory signal is a problem caused by inadequate selection of frequency and sound pressure level ${ }^{[4]}$. Human hearing declines gradually with aging. Elderly people with reduced hearing may not be able to hear sound that can be heard by young people. On the other hand, inability to understand the meaning of the auditory signals is because the signals were set off with different time patterns by product types and manufacturers ${ }^{[5]}$.

To solve this problem, the Association for Electric Home Appliances proposed to establish JIS S $0013^{[6]}$ in 2002 to set frequency and time pattern of auditory signals. In this standard, it was recommended that high frequency sound that cannot be heard by the elderly should not be used, and specific time pattern should be used for auditory signals with certain contents. Hence, frequency and time pattern, two of the three factors that must be addressed when designing auditory signals, were standardized.

The remaining issue was sound pressure level. If volume of the auditory signal is raised, the elderly with reduced hearing will certainly be able to hear. However, it may become a "noisy" sound for young users. Also, there is the issue of domestic sound in the place where the products are used. Auditory signal that can be heard in a quiet place may not be heard in the presence of interfering noise. Moreover, individual differences exist in the level of hearing ability, and the difference is notable in the elderly. The problem of volume setting of auditory signals was raised during the draft review of JIS S 0013, and it was an issue for which solution was strongly sought by consumer organizations and representatives of challenged people's organizations. However, the matter was put on hold since it was not easy to find an appropriate volume setting that could be heard readily by both elderly and young people in various domestic situations.

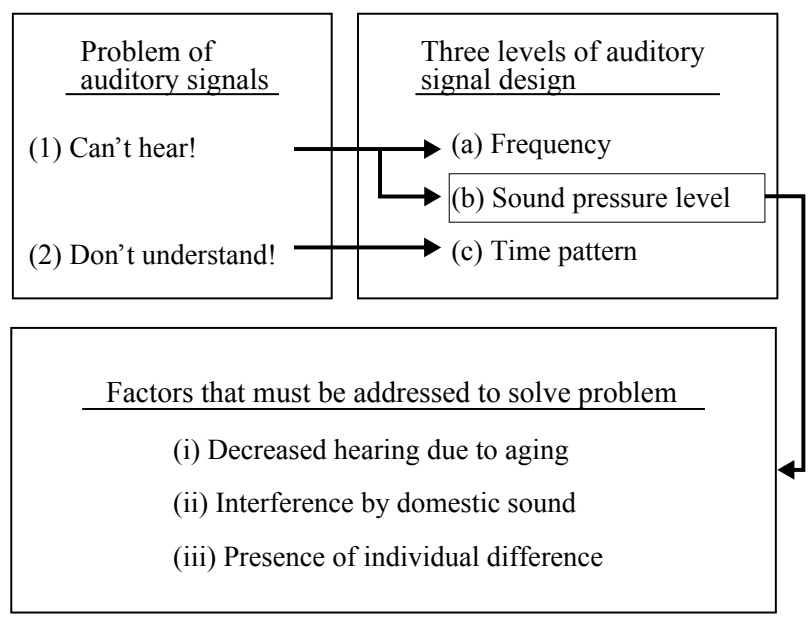

Fig. 1 Problems of auditory signals and issues to be resolved. 
The authors, therefore, addressed the three factors: (i) decreased hearing by aging, (ii) interference by domestic sound, and (iii) presence of individual differences. Then, research was conducted to develop the volume setting method for auditory signals that can be heard readily by both the elderly and the young in actual domestic situations. As a result, JIS S 0014 was proposed and established.

\section{Issues in development of volume setting method for auditory signals}

There were several issues that had to be solved technologically for the three factors and addressed in developing the volume setting method for auditory signals. The solutions taken by the authors for each issue will be summarized using examples of some measurement results.

\subsection{Accommodation of decreased hearing by aging}

The volume setting method for auditory signal must appropriately accommodate the issue of decreased hearing due to aging. For young people, there is a long history of research on hearing sound in interfering noise, and the model for estimating the hearing level has been established. The sound becomes audible when the target sound level is higher than a certain level against interfering sound. Similarly, for the elderly with decreased hearing, it was assumed that whether the target sound could be heard or not can be estimated based on the difference of sound pressure level (SN ratio) of the two sounds. At that time, however, useful data that measured the least SN ratio needed for the elderly or the difference compared to young people did not exist at all.

Therefore, the authors started by measuring the hearing ability in presence of interfering sound for the elderly and young people. Figure 2 shows an example of the results. It

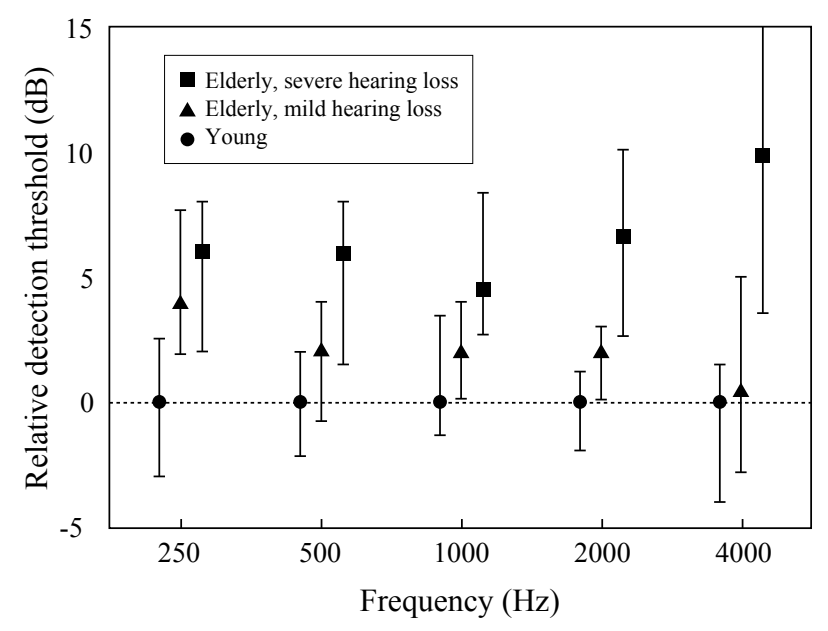

Fig. 2 Sound pressure level necessary for hearing sound in interfering sound (detection threshold).

Revised from Reference [7]. Setting young people as standard (vertical axis, $0 \mathrm{~dB}$ ), relative increase in detection threshold of elderly people is shown. can be seen that even under condition of the same interfering sound, the elderly cannot hear the target sound unless it was $5 \mathrm{~dB}$ higher compared to young people, and $10 \mathrm{~dB}$ for some frequencies in people with severely decreased hearing. From these measurement results, similar level of aging effect in hearing auditory signals in actual environment was anticipated.

Next, based on the above basic findings, sound pressure level of auditory signals needed in presence of real domestic sounds must be estimated. The problem was that the interfering sound used in the experiment described in Figure 2 was a relatively simple noise, but domestic sounds fluctuated in both time and frequency. The audibility of signals changed depending on type and scale of change. However, it is not realistic to experimentally investigate the auditory effect of all fluctuations. It was necessary to construct a simplified auditory model based on certain assumptions for a sound detection process.

Looking back at the researches in which the authors were involved pertaining to detection of sound from noise ${ }^{[8,9]}$ and basic research on hearing characteristics ${ }^{[10]}$, it was projected that average energy content, rather than fine time fluctuation in sound, had greater effect on many auditory phenomena. Therefore, it was hypothesized that auditory signals could be heard when the ratio of average volume of auditory signal and interfering noise ( $\mathrm{SN}$ ratio) surpassed a certain value (this was defined as "minimum value").

Also, the level that could be heard clearly by the elderly with decreased hearing should be attained when the volume of auditory signal was raised above this value. Experimental investigation confirmed that the elderly perceived the sound just as loud as young people when the sound reached a certain leve ${ }^{[11]}$. This sound level was defined as "maximum value". By setting the sound pressure level of the auditory signal so it would fit between the minimum and maximum values, the model was simplified for designing auditory signals that could be heard at appropriate level even in the presence of fluctuating interfering sound.

The validity of the hypotheses as well as maximum and minimum values were investigated and measured by hearing

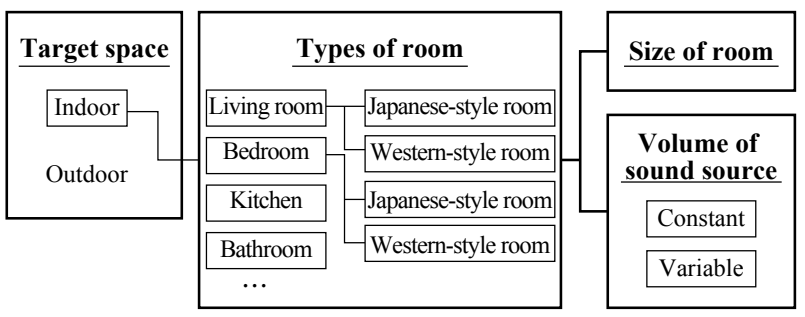

Fig. 3 Range of domestic sounds targeted in domestic sound database JIS TR S $0001^{[12]}$ and factors considered. 
experiment described in Section 4.3.

\subsection{Accommodation of interference by domestic sound}

The places where users use products are varied, and environmental conditions differ greatly. Even if the sound can be heard in a quiet laboratory, if it cannot be heard in an actual use situation, an auditory signal is not appropriately designed. The desired optimal volume needed for auditory signals differs according to the acoustic characteristics such as loudness of interfering noise, structure of frequency component, and time fluctuation. However, it is practically impossible to cover all product use situations and to establish volume setting method for every noise generated. Therefore, it is necessary to simplify the acoustic characteristics of domestic sounds that may be generated in the environment in which the product is used, and create a model that can be verified.

Therefore, prior to the proposal of JIS S 0014, various domestic scenes were assumed and domestic sound database JIS TR S $0001^{[12]}$ that described the acoustic characteristics of typical noise generated in those scenes were compiled. The range of domestic sounds subject to measurement and the factors addressed are summarized in Figure 3.

First, space that will be the subject of study was limited to indoors. Products such as cameras are used both indoors and outdoors, but measurements would increase infinitely if outdoor environment was included. Considering the fact that many consumer products are used indoors, the subjects were limited to sound generated indoors. However, even by limiting the subject indoors, there are several rooms with different noise levels in a house like living room or kitchen. Moreover, sound difference in Japanese and western style rooms could not be neglected.

Volumes of the rooms differed. In a large room, the level of domestic sound differed depending on the location within the room. Therefore, in creating the database, measurements were taken in different locations of the room, and the effects were also described. Also, there were sound sources where volume greatly changed according to the manner of use such as sounds of water in the kitchen or television in the living room. For water sound, measurements were taken at several water volume levels, and for television sound, volume preferred by the elderly was measured in a separate experiment $^{[13]}$.

As a result of the measurements, the database contained over 350 measurements data for 16 types of domestic situations. An example of analysis of domestic sound entered in JIS TR S 0001 is shown in Figure 4. In case of domestic sound, the variation in acoustic characteristic due to differences in houses could not be neglected. Therefore, the database also shows the distribution of measurement values as shown in Figure $4^{[14]}$. By using this database, it is possible to study the degree of difference of noise characteristic in each domestic situation, or the degree of variation of characteristic due to differences in houses.

In general, one would imagine that the domestic sound characteristic would differ greatly if the houses were different. However, as shown in Figure 4, if limited to a single measurement situation, variation due to houses was only about $10 \mathrm{~dB}$ (see the interval between 5 percentile curve and 95 percentile curve in Figure 4). Rather, the characteristic difference between sound of particular measurement situation and another (for example, between water sound of sink and volume of TV in living room) was greater. Therefore, the sound of individual domestic situation was represented by frequency characteristic at 50 percentile value (see Figure 4), and it was assumed that domestic sound produced at home could be covered by selecting several typical domestic situations. Using various selected domestic sounds, auditory signal level that could be heard readily was investigated in an auditory experiment described below.

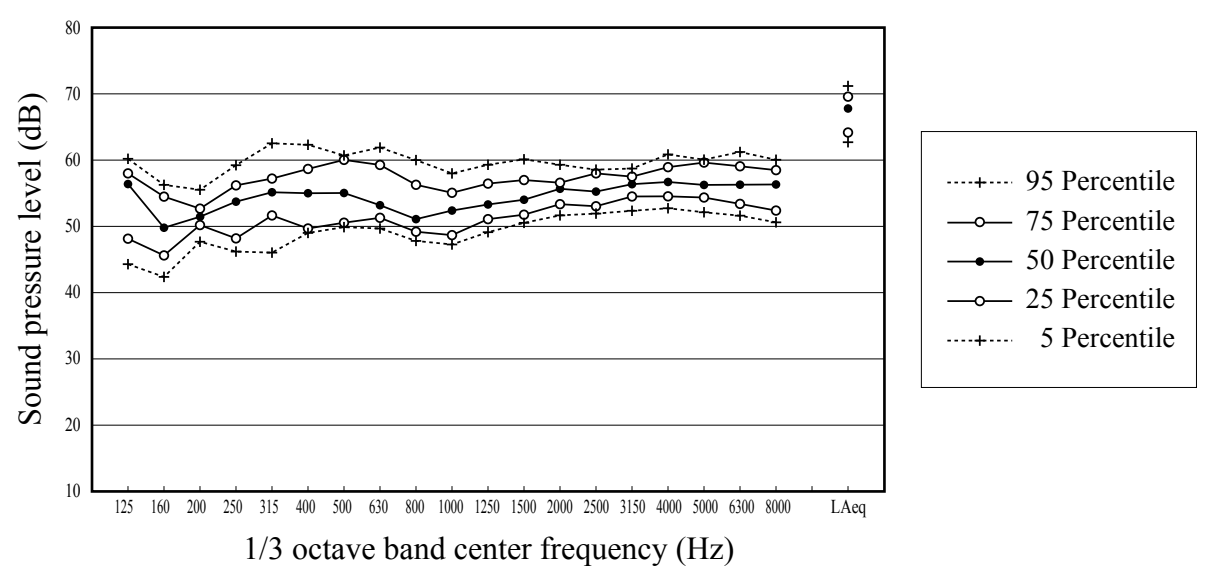

Fig. 4 Example of analysis diagram of domestic sound database TR S $0001^{[12]}$ (sound of washing dishes in sink). Shows the distribution of measurement values in several houses. 


\subsection{Accommodating individual difference}

Based on the investigation in Sections 4.1 and 4.2, appropriate volume setting method for auditory signals could be established by calculating minimum and maximum values of sound pressure level of auditory signals that could be heard in interfering sounds. The last issue remaining was "individual differences". There were individual differences in human perception. Moreover, individual differences increased with age. Therefore, standard value applicable to the elderly could not be found by simply staring at the average measurement data. The proposed volume setting method could not be accepted as standard method unless it could be proven that it satisfied the characteristics of adequate percentage of the elderly. Therefore, it was necessary to experimentally confirm the possibility of universal application of the proposed method by accurately obtaining various measurement values to estimate the statistical distribution of individual differences.

In this study, what percentage of people could hear the auditory signals at which level of volume setting was measured in auditory experiment using several typical home domestic sounds (see Section 4.2). Young people, as well as the elderly, participated in the measurements to compare the differences in hearing characteristics of the two groups. Based on the statistical distribution of the measurement values obtained for the two subject groups, the level of auditory signals that could be heard by adequate percentage (for example $95 \%$ ) (minimum value), and the level which was judged "can be heard well" (maximum value) were estimated for each group. As an example, part of measurement results using the maximum value estimate (in case of $1,000 \mathrm{~Hz}$ auditory signal) is shown in Figure 5.

In this measurement, elderly and young groups rated the audibility of the auditory signal in 5-step evaluation. The marks in the figure show the rating value at about 95

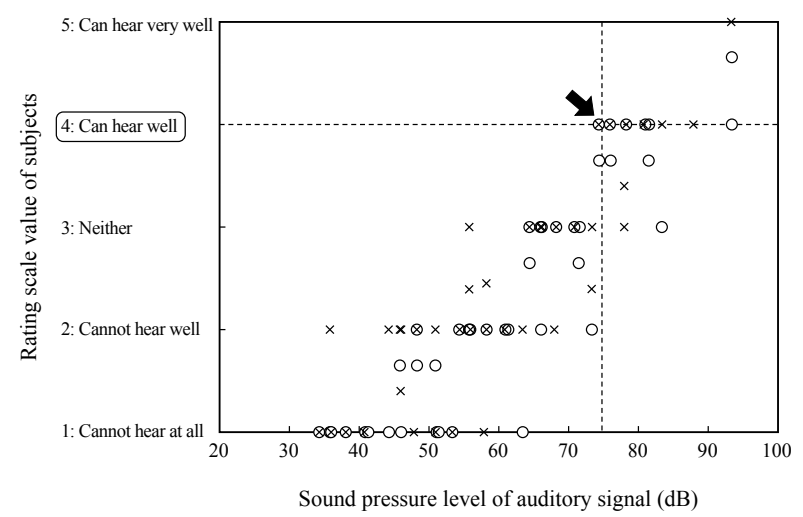

Fig. 5 Example of rating result to obtain maximum value for auditory signal (for $1,000 \mathrm{~Hz}$ auditory signal).

$\circ$ : Elderly group $\times$ : Young group percentile from the top for each group. For example, in the condition marked with "arrow," $95 \%$ of the subjects in each group responded "4: Can hear well" or "5: Can hear very well" in measurement condition using certain domestic sounds. In another word, response of "3: Neither" or lower was less than $5 \%$.

In this figure, "4: Can hear well" rating values (points above horizontal dash line in the figure) are distributed in the range above $75 \mathrm{~dB}$ (vertical dash line in the figure) sound pressure level for auditory signals. That is, in both subject groups, the percentage of subjects who responded "can hear the auditory signal well" at all measurement conditions dropped below $95 \%$ when the auditory signal level was below 75 dB. Conversely, if the auditory signal was above this level, the percentage of subjects who missed the auditory signal would decrease further, but more people would perceive it as being "annoying", so it was not appropriate as volume of auditory signal of products used daily. Therefore, maximum value of the auditory signal was set at $75 \mathrm{~dB}$. For minimum value, similar estimate was conducted for auditory signals of various frequencies based on the results of the auditory experiment.

Overlooking the above analysis results, maximum and minimum values could be set at a certain value in any auditory signal frequency or in any measurement condition using any domestic sound. This confirmed the validity of the auditory model created in Section 4.1. Since the interfering sounds used in the measurements covered almost all characteristics of domestic sounds (Section 4.2), the results of this measurement study should apply accurately to actual domestic situations.

The experiment inevitably increases in scale as measurement data are analyzed statistically to address individual differences. In fact, Figure 5 is based on total 5,600 items of data for 80 elderly and young subjects listening at 70 different condition types. Such large-scale measurement result is the basis for setting the minimum and maximum values for auditory signal volume ${ }^{[15,16]}$.

\section{Volume setting method for auditory signal by JIS S 0014}

Based on the above study result, the volume setting method for auditory signala as described in JIS S 0014 was prepared. The procedure is shown in Figure 6.

First, the sound pressure levels of auditory signal prototype and domestic sound generated in the situation where the product in which the signal will be used (for example, sound of water running in sink if the product is used in kitchen) are measured [Figure 6 (1)]. Second, the sound pressure levels of 
the two sounds are compared [Figure 6 (2)], and whether the auditory signal is audible is determined [Figure 6 (3)]. If the level difference (SN ratio) of domestic sound and auditory signal sits between minimum and maximum values, the volume of the signal is considered to be readily audible. If not, volume of the signal is adjusted [Figure 6 (4)]. Since it is estimated that the auditory signal will be inaudible due to interference of domestic sound if it falls below the minimum value, volume setting of the signal is raised. Conversely, if it is above the maximum level, it is unnecessarily loud, so volume setting is lowered. By going through the above procedures, it is possible to create an auditory signal set at a target volume [Figure 6 (5)].

\section{Characteristic of accessible design technology development compared to conventional human science research}

The process of accessible design technology development was described using as example JIS S 0014 volume setting method for auditory signals. Here, there are two points that differ greatly from conventional human science research from the perspective of Full Research (Figure 7).

First, characteristic data of great number of subjects are collected. In conventional research to clarify the mechanism of human perception or to verify the model (Type 1 Basic Research), discussions are based on measurement data on few subjects (Figure 7, Arrow (1)). There, basic perception mechanism is considered common to all persons, and an "average" person is assumed. Individual differences are normally neglected as a kind of "error".
On the other hand, the subject of research in standardization of accessible design technology is individual differences in perception property including changes due to aging (Arrow (2)). Therefore, data from several dozens to over 100 subjects depending on the study are collected. Individual measurement method and item are no different from the ones used in Type 1 Basic Research. However, human property research that was conventionally limited to the laboratory is extended to a design method that can be used in actual practice by analyzing statistical property of individual differences and universally applying the developed technology (Type 2 Basic Research).

For this purpose, the experimental condition for collecting perception property data must be set not just for conditions limited to the lab but conditions close to the actual home. Therefore, it is necessary to study which conditions should be set and whether the setting represents the actual domestic environment. In case of auditory signals, it was necessary to collect noises that were generated in the actual domestic situation where the products were used, and extract their acoustic characteristics (Type 2 Basic Research). The analysis of domestic sound is not the objective of research, but it is an essential process in testing the validity of the volume setting method for auditory signals.

The second characteristic is that emphasis was placed on simplification of the method. Accessible design technology must be an applicable method in actual product design. Design accuracy may increase by employing an intricate design method and by building a complex model of human perception function (Arrow (3)). However, a complex design

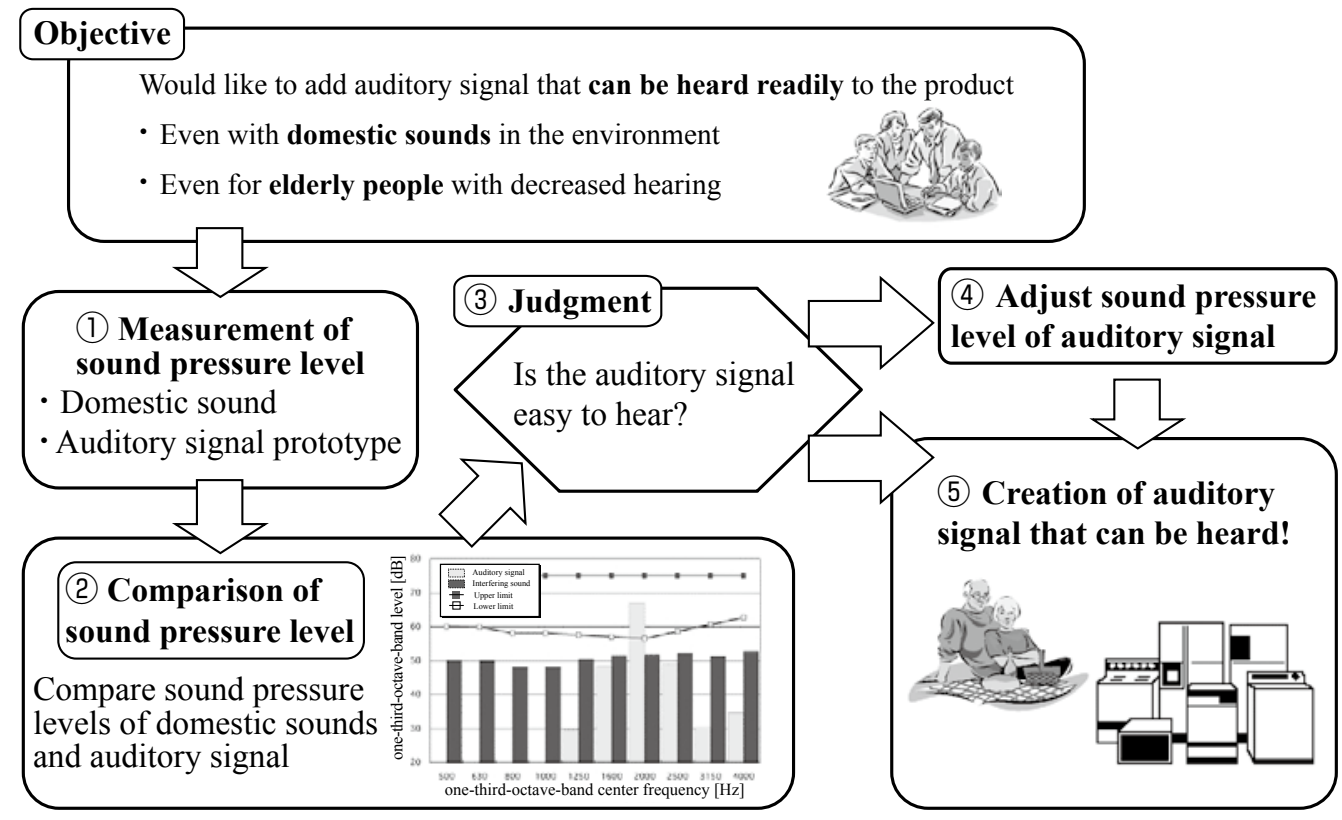

Fig. 6 Schematic diagram of volume setting method of auditory signal established in JIS S 0014 (modified from Reference [17]). 
method cannot be used in actual design practice where cost reduction and speed are crucial (also, the designer may not necessarily be a specialist on hearing or vision). Complex model and method, in general, narrow the range of application. To propagate accessible design, it must be used in various products transcending the barriers of product category. How much the method can be simplified without limiting the application range yet maintaining design accuracy is the most challenging issue in the standardization of accessible design technology (Arrow (4)).

Simplification of the model can be done by trial and error, but it is necessary to employ the basic findings of human property (product of Type 1 Basic Research). In case of auditory signals, it was necessary to simplify the auditory model on hearing auditory signals in noise (Section 4.1). However, it is impossible to study the auditory effect of all fluctuating sound. The model was simplified and experimentally verified, so the ease of hearing could be determined by the volume ratio between noise and auditory signals (SN ratio) by reviewing the general findings of various basic researches on hearing characteristics (Type 2 Basic Research).

\section{Future issues in the standardization of accessible design technology}

\subsection{Accommodating new auditory signals and voice guide}

With the establishment of JIS S 0013 and 0014 , the standardization of basic specifications for auditory signals for consumer products is almost complete. However, requests for new standardizations are being placed by the industry, as auditory signals become prevalent.

First concerns auditory signals with complex acoustic structure. Current JIS addresses relatively simple sound with constant frequency and volume as subject of standardization.

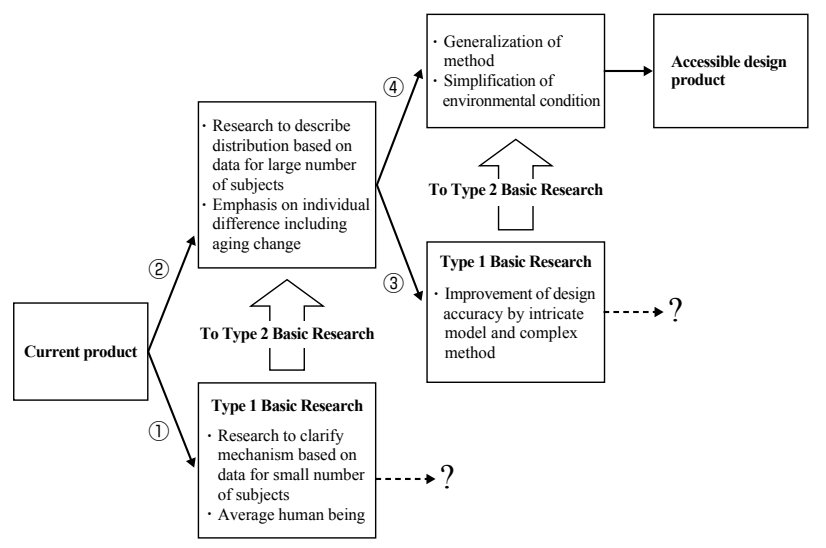

Fig. 7 Steps of accessible design technology development presented in comparison with conventional human science study.
However, with the advance and diffusion of new technology represented by the ringing melody of cell phones, there is interest in using complex musical sound as auditory signals. Second pertains to the use of voice. Products using voice guide instead of simple auditory signals are expected to increase, to communicate more information such as operating instructions to the users.

JIS S 0014 simplified the design method as much as possible, so designers who are not hearing or acoustic specialists can use it. However, authors have received comments that it is still "difficult". Major issue for the future is to develop current JIS into a method that can address more acoustically complex auditory signals and voice guide without increasing the complexity of the procedure.

\subsection{Development of international standard}

Fortunately, JIS Guidelines for the Elderly and People with Disabilities have been employed in designs of many products intended for accessible design. ISO standardization is currently in progress as a step in domestic standardization for guidelines including JIS S $0014^{[17]}$. Like the volume setting method discussed in this paper, the design methodology based on basic human perception property is applicable, in principle, to products of any country. Accessible design technology is expected to be used effectively in countries other than Japan where birthrate is decreasing and the aging population is increasing.

In conjunction with international standardization, the authors are encouraging the standard setters to cite these standards in other product standards to widely propagate accessible design technology. Accessible design technology should become common regardless of the product type or country of production. That is because even if the product is well designed and elderly-friendly, it is inconvenient for the users if non-compatible designs coexist.

Careful manufacturing to match user characteristic and demand is the stronghold of Japanese corporations. If Japanese industry can lead the world market in the field of accessible design, Full Research can be called successful.

\section{Acknowledgements}

Much of JIS Guidelines for the Elderly and People with Disabilities, for which the authors created the draft, are based on the results of foundational research conducted jointly with the National Institute of Technology and Evaluation (NITE). Particularly, the cooperation of NITE was essential in conducting large-scale measurement for perception property of the elderly. We express our gratitude to all people who cooperated. 


\section{References}

[1] Industrial Standards Division, Public Relations Department, Institute for Human Science and Biomedical Engineering: Bogaion oyobi koreisha no choryoku teika o koryo shita hochion ni kansuru hyojunka kenkyu (Standardization research for auditory signal addressing interfering sound and decreased hearing in elderly people), AIST Today, 4(3), 33 (2004) (in Japanese).

[2] Industrial Standards Division, Public Relations Department, Institute for Human Science and Biomedical Engineering: Nendai betsu sotai kido oyobi hikari no hyoka hoho ni kansuru hyojunka kenkyu (Standardization research for evaluation method for relative brightness and light by age), AIST Today, 4(5), 23 (2004) (in Japanese).

[3] Japanese Industrial Standard: JIS S 0014 Koreisha. shogaisha hairyo sekkei shishin - shohi seikatsu seihin no hochion - bogaion oyobi chokaku no karei henka o koryo shita on'atsu reberu (JIS S 0014 Guidelines for the Elderly and People with Disabilities - Auditory Signals on Consumer Products - Sound Pressure Levels of Signals for the Elderly and in Noisy Conditions), Japanese Standards Association (2003) (in Japanese).

[4] K. Kurakata, K. Matsushita, Y. Kuba, and Y. Kuchinomachi: Kaden seihin no hochion no keisoku - koreisha no chokaku tokusei ni motozuku kento dai2ho -(Audio signals in electric home appliances evaluated in terms of the hearing ability of elderly adults (Second report)), Japanese Journal of Ergonomics, 35, 277-285 (1999) (in Japanese).

[5] K. Kurakata, K. Matsushita, Y. Kuba, and Y. Kuchinomachi: Kaden seihin no hochion no keisoku - dai3ho - hatsuon patan no bunseki - (Auditory signals of electric home appliances (Third report) - Temporal ringing pattern-), Japanese Journal of Ergonomics, 36, 147-153 (2000) (in Japanese).

[6] Japanese Industrial Standard: JIS S 0013 Koreisha. shogaisha hairyo sekkei shishin - shohi seikatsu seihin no hochion ( JIS S 0013 Guidelines for the Elderly and People with Disabilities - Auditory Signals on Consumer Products), Japanese Standards Association (2002) (in Japanese).

[7] K.Kurakata, K.Matsushita, A.Shibasaki-K and Y.Kuchinomachi: Detection threshold for pure tones presented against a broadband noise - A comparison of young and elderly listeners -, Proc. 17th International Congress on Acoustics, 4, 3A.15.02 (2001).

[8] S.Namba, S.Kuwano, K.Kinoshita and K.Kurakata: Loudness and timbre of broad-band noise mixed with frequency-modulated sounds, J. Acoust. Soc. Jpn (E), 13, 49-58 (1992).

[9] S.Kuwano, S.Namba, K.Kurakata and Y.Kikuchi: Evaluation of broad-band noise mixed with amplitude-modulated sounds, J. Acoust. Soc. Jpn (E), 15, 131-142 (1994).

[10] S. Namba and S. Kuwano: Shushu no hendo'on no hyokaho to shiteno Leq no datosei narabini sono tekiyo han'i no kento (Psychological study on Leq as a measure of loudness of various kinds of noises), Journal of the Acoustical Society of Japan (J), 32, 774-785 (1982) (in Japanese).

[11] K.Kurakata, A.Shibasaki-K. and Y.Kuchinomachi: Loudness functions of elderly adults for pure tones and low-pass filtered noises, Proc. 7th Western Pacific Regional Acoustics Conference, 191-194 (2000).

[12] Japanese Industrial Standard: TR S 0001 Shouhi seikatsu seihin no hochion nado no sekkei shishin-seikatsu kankyo' on deta besu (TR S 0001 Guideline for Determining the Acoustic Properties of Auditory Signals Used in Consumer
Products - A Database of Domestic Sounds), Japanese Standards Association (2002) (in Japanese).

[13] K. Kurakata, Y. Kuba, T. Kizuka, and Y. Kuchinomachi: Koreisha no choryoku reberu to terebi no choshu onryo no kankei (Relationship between hearing levels of preferred volume levels of television), Japanese Journal of Ergonomics, 35, 169-176 (1999) (in Japanese).

[14] K.Kurakata, K.Matsushita and Y.Kuchinomachi: Database of domestic sounds for evaluation of auditory-signal audibility: JIS/TR S 0001, Acoust. Sci. \& Technol. 24, 23-26 (2003).

[15] K. Kurakata, T. Mizunami, and K. Matsushita: Seikatsu kankyo onchu ni teiji sareta jyun'on shingo no kikitoriyasusa hyoka - jyakunenso to koreisha no hikaku - (Audibility evaluation of pure tones presented against domestic sounds - Comparison between young and elderly listeners -), Proceedings of the autumn meeting of the Acoustical Society of Japan, 459-460 (2002) (in Japanese).

[16] K.Kurakata and K.Matsushita: Japanese Industrial Standards on designing auditory signals of consumer products for the elderly and for use in noisy conditions, Proc. XVth Triennial Congress of International Ergonomics Association, No.713 (2003).

[17] Akuseshiburu dezain seihin no fukyuni muketechokaku shikaku ni kakawaru hyojunka kenkyu no seka o ISO kikakuka tei'an (For the propagation of accessible design products - Proposal for ISO standardization of standardization research result for hearing and vision), Sansoken Today, 7(7), 19 (2007) (in Japanese).

Received original manuscript September 18, 2007 Revisions received November 26, 2007 Accepted November 26, 2007

\section{Authors}

\section{Kenji Kurakata}

Joined the National Institute of Bioscience and HumanTechnology, Agency of Industrial Science and Technology in 1996. Currently, Group Leader of Accessible Deign Research Group, Institute for Human Science and Biomedical Engineering of AIST. Engages in research on hearing characteristics of the elderly, and works on drafting proposal for JIS in auditory and acoustics field and on international standardization activity. Worked on ISO/TC 159 (Ergonomics)/SC5/WG5 Convenor, ISO/TC 43 (Acoustics) /WG1 Expert, and others. Spends effort to propagate accessible design technology with belief that creating environment and products that can be used readily by older elderly people and people with disabilities will lead to a society where everyone can live comfortably.

\section{Ken Sagawa}

Joined the National Institute of Industrial Products and Research Institute Science, Agency of Industrial Science and Technology in 1975. Currently, Prime Senior Researcher of the Institute for Human Science and Biomedical Engineering of AIST. Engages in research on photometry and visual environment evaluation through psychophysical measurement of vision. Has developed mesopic photometry system, scaling of comfortable color environment, measurement of visual characteristics of elderly people and people with disabilities, and propagation through 
standardization as JIS and ISO of the research results obtained. Currently works in international standardization activities including executive secretary of Commission Internationale de l'Eclairage and ISO/TC 159 (Ergonomics) / WG2 Convenor.

\section{Discussion with reviewers}

\section{Research process and structure of paper Question (Motoyuki Akamatsu)}

It will be better if an overall structure is presented that reveals the researcher's thinking "why standardization is best choice" for accessible design, specifying the demands, for example, the efficacy of standardization in accessible design, conditions for such standardization, and data collection based on these, and then providing the solutions. If the processes are clearly explained, as whether standardization is best, and if so, what kind of standard is good, it would be a great help to the readers.

Question (Hisao Ichijo)

Flow of the research is explained, but I think the elemental technology and the selection and integration process are somewhat unclear.

\section{Answer (Kenji Kurakata)}

By making the following revisions, overall structure was changed as indicated, and I think the significance and advantage of the standardization research were clarified.

-Addition of Section 2 on significance and importance of standardization

-Adjustment of explanation of Section 3 that summarizes design issue of auditory signal

- Revision of explanation of Section 5 on the actual application of the standard

\section{On research subject \\ Question (Motoyuki Akamatsu)}

It would be better if you mention detailed issues as well as the main framework of the subject. For example, in actual domestic environment, distances between the device and the user are varied, or there may be furniture between them. There are rooms with strong reverberation and dead rooms, and there may be differences because of them. It would be better to clarify to what degree issues were considered and reasons they were selected as research subjects.

\section{Answer (Kenji Kurakata)}

For detailed issues on domestic sound, we added explanations in "4.2 Accommodating interference by domestic sounds". For hearing characteristic of the elderly, we explained the technological issues in "4.1 Accommodating decreased hearing due to aging". I believe these additions will clarify the thought process that the authors went through.

\section{On evaluation of research result Question (Motoyuki Akamatsu)}

I think you should show the level you achieved as research goal that you initially set and do a self-evaluation. I expect you to mention whether the resulting JIS is satisfactory or still unsatisfactory from the eyes of the authors.

Answer (Kenji Kurakata)

I think we achieved almost all research goals set initially for the technology established as JIS. However, due to technological advances that followed, new issues arose such as the use of auditory signals that cannot be accommodated by current JIS. This point is explained as future development in "7.1 Accommodating new auditory signal and voice guide", and this shall serve as our self-evaluation of the current status. Also, measures to propagate JIS are discussed in detail in the same section and "7.2 Development of international standardization".

\section{On thinking about model simplification Question (Hisao Ichijo)}

I think it will be better to explain the process that lead to your thinking: average energy level greatly affects auditory phenomenon and simplification is the essence of the model.

Answer (Kenji Kurakata)

This thought process was achieved as an extension of the research that I have been previously involved in, so I cited References $[9,10]$. Also, I clarified the authors' thought process by providing more explanation in "4.1 Accommodating decreased hearing due to aging".

\section{Correlation between this research and Type 1 Basic Research Question (Akira Ono)}

Conventional research and this research are compared in Figure 7, and (2) and (4) are positioned as Type 2 Basic Research, while (1) and (3) are positioned as Type 1 . I highly evaluate the fact that the authors succeeded in achieving the goal of standardization of accessible design by intentionally taking Type 2 Basic Research method. However, I feel that the results of (1) and (3) that are positioned as Type 1 Basic Research may have some kind of significance in this research.

For example, can't research (3) be used to review, although perhaps partly, the validity of result of (4) that was reduced and simplified, since research (3) can present a complex and accurate model?

Also, I think research (1) presents an average person, but doesn't it support the base of research ni (2) that explains the variation and diversity of people? I would like to hear the authors' comment.

Since the reviewer holds image that Type 2 Basic Research is built upon the base of related Type 1 Basic Research result, I ask this question from my interest of seeing what kind of correlation there is in this study.

\section{Answer (Kenji Kurakata)}

I think you have made a clear point. As questioned, I think the standardization research for accessible design technology that the authors conducted fits the framework of "Type 2 Basic Research is built upon the base of related Type 1 Basic Research result". That is, the characteristic of this research is "sublimation" of Type 1 Basic Research result on human property to design method applicable to actual practice through Type 2 Basic Research including consideration of environmental conditions.

Also in Figure 7, presenting the comparison of this research and conventional research in either-or format was inappropriate. The figure should present the fact that combination with Type 2 at point of maturity, and then converting to Full Research, although understanding the necessity and importance of Type 1, were useful in realizing accessible design product.

Considering this point, in the final version, we inserted a figure that clarified the relationship between Type 1 and Type 2 Basic Researches. 